Article

\title{
Ranked Choice Voting in Australia and America: Do Voters Follow Party Cues?
}

\author{
Benjamin Reilly \\ School of Social Sciences, University of Western Australia, Crawley, WA 6009, Australia; E-Mail: ben.reilly@uwa.edu.au
}

Submitted: 1 December 2020 | Accepted: 1 March 2021 | Published: 15 June 2021

\begin{abstract}
Ranked choice voting (RCV) is experiencing a surge of interest in the United States, highlighted by its 2018 use for Congressional elections in Maine, the first application of a ranked ballot for national-level elections in American history. A century ago, the same system was introduced in another federal, two-party continental-sized democracy: Australia. RCV's utility as a solution to inter-party coordination problems helps to explain its appeal in both countries, underscoring the potential benefits of a comparative analytical approach. This article examines this history of adoption and then turns to a comparison of recent RCV elections in Maine with state elections in New South Wales and Queensland, the two Australian states which share the same form of RCV as that used in the United States. This comparison shows how candidate and party endorsements influence voters' rankings and can, over time, promote reciprocal exchanges between parties and broader systemic support for RCV. Such cross-partisan support helps explain the stability of RCV in Australia, with implications for the system's prospects in the United States.
\end{abstract}

\section{Keywords}

Australia; democracy; elections; electoral system; preferential voting; ranked choice voting; United States of America

\section{Issue}

This article is part of the issue "The Politics, Promise and Peril of Ranked Choice Voting" edited by Caroline Tolbert (University of lowa, USA).

(C) 2021 by the author; licensee Cogitatio (Lisbon, Portugal). This article is licensed under a Creative Commons Attribution 4.0 International License (CC BY).

\section{Introduction}

Ranked choice voting (RCV) is experiencing a surge of interest in the United States. Advocated as a means of delivering more majority-supported victors and addressing broader problems of polarization, incivility and vote-splitting under plurality rules, RCV has been adopted for mayoral and other local elections in major United States cities such as San Francisco, Oakland, Minneapolis, and Santa Fe. Most importantly for this article, after repeated initiative ballots and legal challenges, was RCV's adoption for United States Congressional elections in Maine, and its first use at the November 2018 mid-terms.

This historic first use of a ranked ballot for United States national elections invites comparison with other jurisdictions using RCV in similar partisan, large-scale contests. A particularly relevant comparative case is
Australia-another continental-sized federal two-party democracy that has used RCV for state and national elections for over a century. Australia's extended use of RCV in both single-member majoritarian (in the federal House of Representatives and most state lower houses) and multi-member proportional (in the Senate and most state upper houses) forms has seen Australian politics develop distinctive adaptations to 'preferential voting,' as RCV is known locally. As this article will show, some of these are directly relevant to the United States, while others are unlikely to be part of the American $\mathrm{RCV}$ experience.

Key in both countries is how parties and candidates respond to the presence of a ranked ballot in terms of their campaign strategy. This article examines the process by which parties and candidates seek and reciprocally offer secondary rankings in their quest for electoral victory. In Australia, such 'preference swapping' 
arrangements are usually made between parties which share some degree of ideological affinity, and communicated to voters via another distinctive Australian adaptation to RCV: 'how-to-vote' cards that detail each party's suggested ordering of rankings amongst all candidates standing for a seat. These are distributed outside polling booths by party operatives, seeking to ensure prospective voters cast a valid vote and follow the party's preference-swapping deals as closely as possible. By contrast, in the more recent and localized American use of RCV to date, such prompts and voter cues are more likely to be communicated at candidate debates or through the media.

How closely voters follow their favoured party's ranking cues can determine not just who wins and loses a seat, but also the extent to which RCV encourages broader campaign civility, moderation and collaboration (Donovan, Tolbert, \& Gracey, 2016; Reilly, 2001). It is thus a key indicator of RCV's effectiveness as a political reform. This article examines this issue by comparing Maine with the two Australian states, New South Wales and Queensland, which share the same form of RCV. Candidates, parties and affiliated groups all influence voters' use of rankings. As I will show, the willingness of parties and candidates to advocate-or withholdendorsements of secondary rankings for rivals can determine the outcomes of closely-fought contests such as Maine's 2nd Congressional District RCV election in 2018, and similar races which feature multiple candidates who share overlapping policy platforms and ideology.

\section{Some Background}

By requiring winners to obtain an absolute majority of the vote (either outright or after the distribution of preferences), RCV offers different routes to victory than plurality elections. While in practice most RCV contests are won by the same candidate who leads in the first-choice count, this is not always the case. At Australia's 2016 federal election, for instance, $11 \%$ of all seats were won by candidates who were not the first-round plurality leader, while (as discussed later in this article) Maine's first RCV election also saw such a 'leap-frog' (Maloy, 2019) or 'come-from-behind' (Reilly \& Stewart, 2021) result. In such cases, RCV advantages candidates who can garner not only a competitive first-choice vote but also a healthy flow of second-choice votes from supporters of other candidates. This encourages broader pre-election appeals and party collaboration than would occur under otherwise-identical plurality voting procedures.

I have argued elsewhere that Australia's extensive and extended use of RCV is one reason that electoral competition there has remained largely centrist (Reilly, 2001, 2016, 2018), in contrast to the United States. Despite the different contexts, the fundamentals of single-member RCV are identical in both countries: Voters provide an ordinal ranking of candidates standing, and any candidate who wins an absolute majority of first- choice votes is elected immediately. If no candidate has an outright majority, the candidate with the lowest number of first-choice votes is eliminated from the count and their ballots transferred according to each voter's second (and, if necessary, later) rankings. This process continues until one candidate has gained a majority of votes left in the count, and is elected.

However, there are also some important differences between American and Australian practice. Most Australian jurisdictions compel voters to express a ranking for all candidates standing. Along with Australia's other forms of electoral compulsion-compulsory enrollment and compulsory voting-this 'compulsory preferential' form of RCV largely removes from parties the need to get out the vote, and ensures a much more reliable flow of preferences from minor parties back to one of the two major parties (Reilly \& Maley, 2000).

By contrast, in San Francisco and some other United States RCV elections, electors are limited to a maximum of three preferences due to the configuration of voting machines, with the ballot based on machine-readable selections by column rather than the hand-written numerical rankings used in Australia. This enables 'overvotes' to be identified and corrected before they are lodged, making for much lower levels of invalid votes than at Australian elections, where numbering errors, blank ballots and protest votes are all a feature of the compulsory system (Kimball \& Anthony, 2017).

Figure 1 illustrates these different ballot designs from three different RCV elections: the first from Maine, the second from a compulsory preferential Australian federal election, and the third from an optional preferential New South Wales state election. Maine's voters are instructed to rank a first choice, a second choice "and so on... continue to rank as many or as few candidates as you like." In New South Wales, the instructions are to number a first choice, with the rider that "you can show more choices, if you want to, by writing numbers in the other squares." By contrast, at Australian federal elections, voters are told explicitly to "number every box to make your vote count."

These differences reflect the history of RCV's adoption in each case. Australia borrowed liberally from the United States when choosing its national governing institutions at federation in 1901: dividing and sharing sovereignty between national and state governments via federalism, with a bicameral elected legislature featuring a popular House of Representatives and a Senate to represent State interests, a written constitution interpreted by the highest court in the land, and so on. But in contrast to the American experience, in Australia the drawbacks of plurality elections were highlighted in early constitutional debates and were soon manifested in elections to the new federal and state assemblies in the early decades of the 20th century.

In 1907, the state of Western Australia became the first jurisdiction to adopt RCV as a means to save the costs of a runoff election, promote more civic 

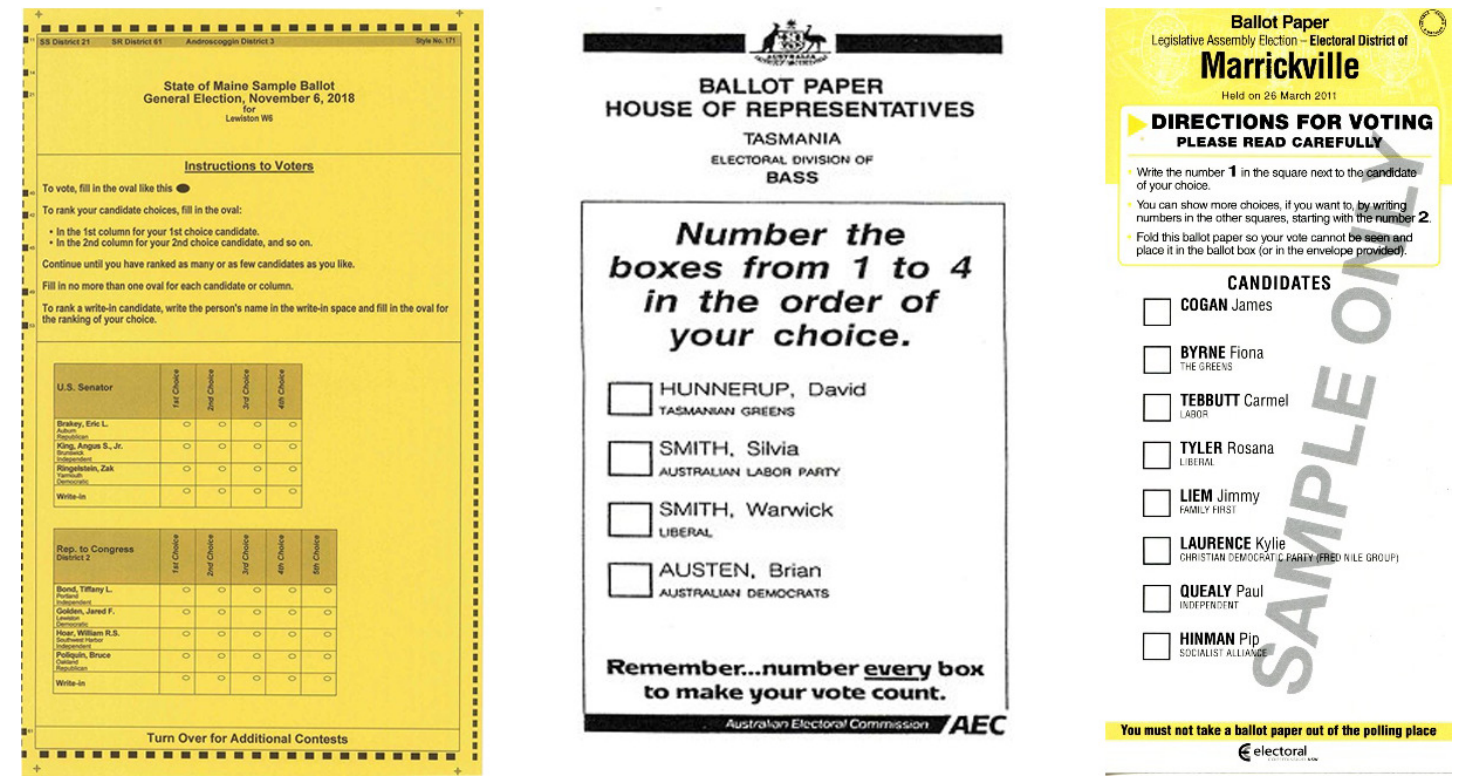

Figure 1. Three RCV ballot papers from Maine (Congressional), Australia (federal-level), and New South Wales (state-level).

engagement in the electoral process, and enable majority rather than plurality victors, as well as sparing Australian parties the need to run primary elections (Phillips, 2008, p. 44). However, the first state election held under RCV in 1908 was only partially successful in meeting these aims, as parties continued to present multiple candidates and many voters expressed only a first choice, making rankings ineffective (being counted in only eight of the 50 electorates, and changing the results in none). This undermined the aggregation potential of preferential voting, and made its operation in practice analogous to a plurality race.

In the United States, similar plurality-like outcomes were used to justify the repeal of RCV after its first wave of use in the early part of the 20th century. For instance, RCV rules for party primaries in Maryland, Indiana and Florida were all repealed in the 1930s, after successive elections in which relatively few voters expressed preferences beyond the first, delivering results indistinguishable from a plurality contest (Hughes \& Santucci, 2017). In Australia, by contrast, the widespread non-use of preferences offered legislators the opportunity to make rankings mandatory, an idea that had been raised in earlier constitutional debates and presented political advantages for the dominant conservative side of politics in ensuring a degree of inter-party coordination. In 1911, before its second RCV election, Western Australia therefore made it compulsory for voters to express rankings for all candidates in order to effect a valid vote. Those who ranked only one or some candidates had their vote invalidated in most cases.

This change, little discussed at the time, proved to be highly consequential and was soon replicated by other states and the federal government. With party systems in an embryonic stage and the consequence of preference flows difficult to predict, the benefits of ensuring that these occurred by law if not voter choice proved particularly attractive to parties on the conservative side of politics, whose vote was often split between multiple rural and urban parties. Conservative interest in RCV peaked after a 1918 by-election was won by Labor with $35 \%$ of the vote despite the three non-Labor candidates collectively mustering $65 \%$. The introduction of RCV with compulsory preference marking for national elections soon after sought to address these recurring coordination problems by allowing conservative urban and rural parties to cooperate, aggregating their votes to build majority victories over a plurality-leading Labor candidate (Graham, 1962).

On the face of it, this experience has some similarities with the more recent and episodic introduction of RCV for primary and city elections in the United States, where the emergence of third parties alongside ruling-party splits often made new reform alliances possible (Santucci, 2017). Upon closer examination, however, there are important differences. In Australia, with no primary elections (local branches pick candidates, but can be over-ruled by the national party executive), RCV was usually seen as a desirable end-point in itself, while in the United States it has often been seen as a stepping-stone towards broader reforms such as proportional representation (Amy, 2002; Drutman, 2019; Richie, 2004). Only in recent years, with $\mathrm{RCV}$ emerging as a viable reform for Congressional elections, have the virtues of majoritarian aggregation been championed (Diamond, 2017).

A possibly uncomfortable lesson for United States reformers from the Australian experience is that singlemember RCV has never led to proportional representation. Instead, once single-member district elections changed from plurality to RCV, they stayed there. Indeed, once adopted federally, it took only a few decades for RCV to spread across the continent-from Western 
Australia and Victoria (which had adopted the system in 1916) and then on to New South Wales (1928), South Australia (1936) and eventually Queensland (1962). By the early 1960s, single-member RCV was the law of the land for all lower houses save Tasmania, which uses a proportional form of RCV (Farrell \& McAllister, 2006).

Key to this relatively smooth progression and adoption of RCV was the electoral interests of conservative parties, who found that compulsory preferential voting delivered a reliable flow of preferences from smaller parties to their right. By contrast, the Labor Party found themselves at an electoral disadvantage, and for many years sought to return to plurality voting or introduce optional preferences. By the 1980s, however, this began to change, as the rise of post-material and environmental politics saw Labor start to benefit from increasing flows of preferences from parties to their left, such as the Australian Democrats and later the Australian Greens. As Labor became the beneficiary of a system it had long opposed, it also became a strong supporter of compulsory rankings, from which it now greatly benefits. As Peter Brent (2018) has detailed, this structural advantage has been increasing for decades, with Labor increasingly advantaged by preference transfers compared to the centre-right Coalition (i.e., the Liberal and National Parties in a long-term alliance; see Figure 2).

Despite this partisan imbalance, RCV has to date retained the support of all the main Australian parties, albeit for different reasons. While the federal Coalition has over time become a net loser from RCV in electoral terms, they have so far continued to support the system in part because it helps maintain their long-standing coalition arrangement. In so-called 'three-corner' contests in which National, Liberal and Labor candidates as well as minor parties and independents stand, compulsory RCV helps avoid vote-splitting between different parties and affiliated groups from the political right, a concern today just as it was a century ago. Minor parties of the political left such as the Australian Greens also support RCV, seeing it as a means for them to wield influence on the major parties.

By lessening uncertainty for the major parties over the quantity and direction of rankings, compulsory preferential RCV also makes elections more predictable and reinforces the status quo. Recommendations from scholars to revert to optional preferential voting, as used in the United States and indeed all cases of RCV outside Australia, have to date attracted little enthusiasm (Farrell \& McAllister, 2006, p. 179; Reilly \& Maley, 2000, pp. 37-58). However, in late 2020, a Coalition-dominated parliamentary committee called for optional preferential voting to be introduced for future federal elections, signalling a potential change in this long-standing consensus (Reilly \& Stewart, 2021).

By making lower house electoral politics a contest for the middle ground, RCV in Australia has also served as a prophylactic against political extremism. At times, the two major parties have even swapped preferences with each other to eliminate perceived systemic threats, such as the emergence of the far-right One Nation party in the late 1990s (Reilly, 2001, pp. 53-54). This stands in sharp contrast to the situation in the United States today, where voters often face polarized choices at both primary and general elections under plurality rules, forced to choose between relatively extreme candidates (Bartels, 2016), and where the two main parties face perverse incentives towards negative campaigning and other zero-sum strategies. By introducing some elements of a positive-sum game-whereby votes for a rival can still flow back to your party via transfersRCV offers a potential circuit-breaker to this 'doom loop' (Drutman, 2019).

Supporting this contention, studies of RCV elections in San Francisco, Oakland, Minneapolis and other American cities have mostly affirmed that RCV elections are less negative and more cooperative than equivalent

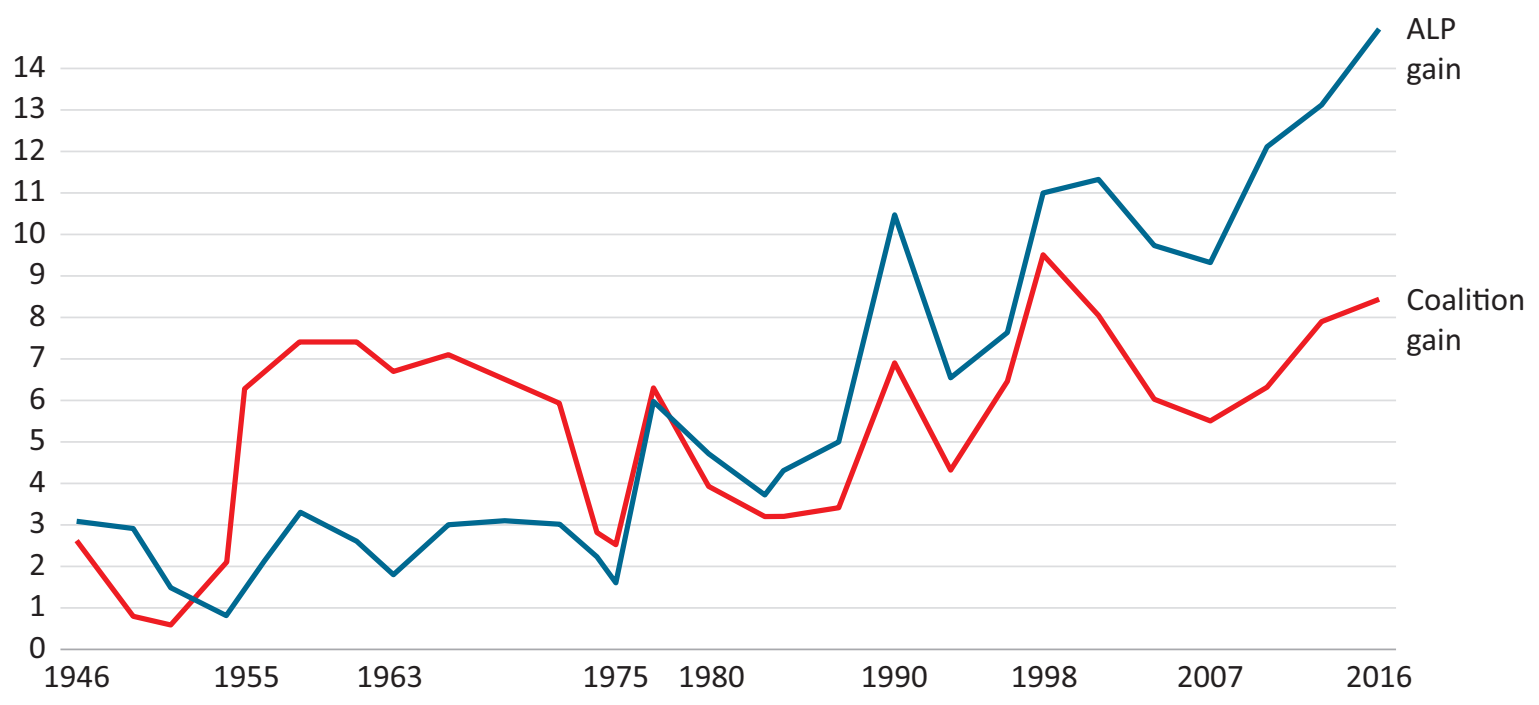

Figure 2. Major parties' gains from preferences at federal elections (\%), 1946-2016. Source: Brent (2018). 
contests held under plurality rules (Donovan et al., 2016). Opinion polls have also presented significant confirming evidence that RCV increases electoral moderation when compared to control cases using plurality voting (Fairvote, 2015). Despite this, court challenges and repeal movements remain a feature of RCV in the United States, even as burgeoning reform movements push for the system's nationwide adoption. As Santucci (2018, p. 4) notes:

RCV in the U.S. has been repeal-prone. Recent enactments in Pierce County (WA) and Burlington (VT), for example, lasted just a few years each. Voters in Ann Arbor (MI) used RCV for only one election, in $1975 \ldots$...Passing RCV today far from guarantees its permanence.

The varying treatment of rankings-optional versus compulsory-offers one potential explanation for the relative stability of RCV in Australia compared to the United States. By ensuring a reliable flow of rankings from supporters of smaller parties to larger ones, Australia's system of mandatory rankings has seen most parties grow to support RCV, with the majors seeking to harvest minor party preferences, and the minors seeing it as a means to improve their influence on major parties. Both are underpinned by 'cross-house' preference deals, in which parties' varying focus on lower and upper houses creates an opportunity for arbitrage between the two (Sharman, Sayers, \& Miragliotta, 2002). As a result, RCV retains broad political support in Australia, to the point where alternatives are seldom considered. In the United States, by contrast, opponents of RCV have been able to organise resistance based not just on political interest, but also by making claims about RCV's complexity, administrative efficiency, and constitutional fealty.

The historic first-use of RCV for national elections in Maine in 2018, discussed below, presented a key test case for many of these claims. As a full-blooded partisan contest, it also invites direct comparison with the Australian experience. But in order to compare like with like, such a comparison needs to be with cases of optional rather than compulsory rankings. Two Australian states, New South Wales and Queensland, use (or in the case of Queensland, used) such a system, where the decision to express secondary and later preferences is left up to the voter rather than compelled in electoral law. Their masslevel partisan elections to state legislatures also provide a much better framework for comparison with Maine than the mostly non-partisan city-level applications of RCV elsewhere in the United States.

The remainder of this article therefore compares the relationship between party cues and voter rankings from 2015 elections in both Australian states with Maine in 2018. Appeals for secondary preferences made a difference to electoral outcomes in all cases-changing the strategic incentives for candidates compared to a plurality contest, and the likely results, in a number of cases. However, this comparison also highlights the broader challenges of behavioral adaptation by voters and politicians facing a new and more complex voting system-as was the case in Maine in 2018-and the need for intra-party coordination in tight races involving both major and minor parties, as well as independents, under RCV.

\section{Parties and Preferences at Recent Australian State Elections}

As noted earlier, Australian parties typically distribute 'how to vote' pamphlets outside polling places to convey to intending voters a preferred preference ordering amongst the candidates standing. Examination of the relationship between such party cues and the actual rankings made by voters can quantify the extent to which voter behavior can be steered by such suggestions. Such appeals are usually made on the basis of reciprocitythat is, an expectation that an offer by one party to recommend their supporters provide lower-order rankings for a rival candidate will see that party or candidate do likewise with their own voters. In Australia, these 'preference-swapping' deals rely on a combination of ideological affinity between parties and naked political calculation, and are typically negotiated by party secretaries rather than individual candidates.

Ballot paper surveys conducted in 2015 at state elections in both New South Wales and Queensland (Green, 2018) show how such deals influence voters' choice of whether and who to rank under RCV. While overall most voters followed the 'how-to-vote' recommendations of their favored party, there was considerable partisan variation. In New South Wales, for instance, the proportion of single rankings by Labor voters reached $72 \%$ in the 21 electorates where this strategy was recommended by the Labor Party's campaign material, and fell sharply when Labor how-to-vote cards instead suggested a partial or full preference recommendations. The rate of both full and partial preferencing doubled in those electorates where this was recommended, compared to suggestions that a single preference only be marked. For instance, recommendations that Labor voters give their second preference to a Greens candidate in some seats resulted in a $20 \%$ increase in preference flows compared to the control cases of no recommendation.

A similar pattern was evident amongst Greens voters. In seats where the Greens recommended a single ' 1 ' vote for their candidate only, the rate of exhausted preferences was $53 \%$ and the flow of second preferences to Labor $31 \%$. Where the Greens recommended a second preference for a third party, the flows were $28 \%$ to such third parties and $24 \%$ to Labor. Where the second preference recommendation was for Labor, its share lifted to $38 \%$. Averaged across all electorates, the willingness of Greens voters to express a second preference increased by $10 \%$ simply as a result of this being suggested on their 'how-to-vote' cards. 
These patterns were largely replicated in a similar ballot paper survey conducted at what was the last optional preferential election in Queensland, also held in 2015. There, where the Greens recommended a second preference for a third party, the flows were $43 \%$ exhausted, $28 \%$ to that third party, and $24 \%$ to Labor. Where the second preference recommendation was for Labor, flows to Labor jumped to $38 \%$. Not only did Greens voters give second preferences at a much higher rate when they were asked to than when they were not, but an additional $15 \%$ of available preferences went to Labor candidates when this was suggested by the Greens to their supporters.

The varying approaches to such party recommendations appears to hinge on the marginality of the seat concerned. The tighter the contest, the more likely it is that parties will seek and voters offer preferences to rival but politically cognate or aligned candidates, and hence (in these examples) the stronger the coordination between Labor and Green parties and their preference flows. It was in this way-by asking for and receiving the preferences of Greens voters - that Labor won three seats from second place on preferences at the 2015 NSW election (Green, 2015).

In sum, preference endorsements matter in RCV elections, and they particularly matter in close contests. Under conditions of electoral uncertainty, where secondary preferences may be the difference between victory and defeat, it makes sense as an a priori electoral strategy to signal this willingness to one's supporters, if only for the potential opportunity to receive preference flows from rivals in return.

\section{Parties and Preferences in Maine's Second Congressional District 2018}

The Australian experience is pertinent to Maine's 2018 and 2020 RCV elections-especially the 2018 2nd Congressional District race, the only one of the state's RCV contests that has so far gone to preferences (as did the 2018 Democratic gubernatorial primaries). All other $\mathrm{RCV}$ races to date have been won by absolute majorities in the first round-resulting in the re-election of incumbent Senators Angus King (I) in 2018 and Susan Collins (R) in 2020, incumbent 1st District Representative Chellie Pingree (D) in both years, and incumbent 2nd District Representative Jared Golden (D) in 2020.

The 2018 contest for Maine's 2nd Congressional District was another story. The first round of counting produced no majority victor, with just 2,171 firstranked votes separating the incumbent, Republican Bruce Poliquin (46.3\%) from Democrat challenger Jared Golden (45.6\%), with two independents splitting the remaining $8 \%$ of the vote between them. Winning an RCV election in such circumstances depends not just on having a strong first-preference vote, but on gaining transfers from excluded candidates. However, the candidates adopted very different strategies in this regard.
At an October 2018 candidate debate in the lead-up to polling day, Golden and the two independents all publicly pledged that they would preference each otherthereby signalling to their supporters to do likewise. Republican incumbent Poliquin, by contrast, spurned the idea of giving or asking for any second or third choice votes. This was a folly, as second preference votes in such a close race could (and as it turned out, did) provide the margin of victory.

Post-election ballot analysis by Alvarez-Rivera (2018) showed that, as in Australia, most voters in the 2nd District followed their chosen party's signalling. About two-thirds of Republican voters cast a single ranking for Poliquin only, as he had effectively suggested, while for Democrats this pattern was reversed, with over $60 \%$ of Golden voters ranking at least one other candidateand even higher preferencing rates by supporters of the two independents in the race, Tiffany Bond (73\%) and William Hoar (69\%). Consequently, in the second round of counting Golden received over twice as many preferences from these two excluded candidates as did Poliquin-45\%, compared to $20.5 \%$ - with a further $34 \%$ expressing no preference between the two major party candidates, and thus exhausting. This difference effectively determined the final result, a come-from-behind win for Golden with a margin of just under 3,000 votes after the batch elimination of Bond and Hoar.

Poliquin's dismissal of the logic of RCV saw him become the district's first incumbent to lose re-election in more than a century. Having earlier claimed that the new system was unconstitutional, Poliquin filed a lawsuit to stop the Secretary of State's tabulation of ballots before a winner could be announced. Poliquin lost this case and then appealed to the First Circuit to halt the certification and stop Golden from being seated. After Poliquin was unable to prevent Golden from taking office, he withdrew his appeal. Once all lawsuits were dismissed and the count was completed, Golden was declared the winner with a $50.62 \%$ majority. At the final certification of results, outgoing Governor Paul LePage scrawled "stolen election" on the official papers (Fried \& Glover, 2018), in reference to Golden's come-from-behind victory. But such 'leap-frog' results are a feature, not a bug, of RCV, which can penalise polarizing candidates "with a sizeable core of loyal supporters but little appeal beyond them" (Maloy, 2019, p. 115).

The Australian comparison strongly suggests that by ignoring the strategic imperatives inherent in RCV, and recommending a single vote only with no rankings, Maine's Republican Party effectively deprived themselves of the potential benefits of receiving reciprocal preference flows from excluded candidates. This may have made sense as a broad statement of opposition to RCV, but it was a self-defeating strategy in the 2018 2nd Congressional District race, which was known ahead of time to be a close contest. In safe seats where a candidate feels assured of winning, they have less incentive to reach out for second and later rankings. In tight 
contests, by contrast, every vote counts, and preferences from other candidates' supporters could be the margin between victory and defeat.

What both the comparative evidence from relevant Australian elections and the particulars of Maine's 2nd Congressional District race suggest is that had Republicans appealed for such second-choice votes, the result may well have been different. Either of the two eliminated independents received sufficient first-choice votes to make this a viable strategy. Even the lowest placed independent candidate, William Hoar, who ran on a rural-focussed platform, received 6,875 votes, and could have been a viable candidate for such an appeal. As it was, the total number of exhausted votes $(7,820)$ were more than twice the margin of victory. While Maloy (2019, p. 115) suggests that "political professionals do not have to experience a leap-frog defeat before they can grasp that the system makes it possible, and they tailor their approach to voters accordingly," this did not seem to occur to Maine's Republican Party operatives in 2018.

This unwillingness to adapt to the strategic logic of RCV was not the only reason for the outcome, of course. There were other factors at play: the falling popularity of the Republican candidate and indeed of the party brand in Maine, and counterfactuals such as how many votes Poliquin would have lost had he chosen to reach out to other candidates in this way (presumably some Republican voters would have been put off by such an approach). Nonetheless, with an eventual margin of just 3,809 votes, the decision by Poliquin and the Republican Party leadership to explicitly reject the idea of either giving or receiving second and later rankings was a flawed political strategy that resulted in the loss of a potentially winnable seat.

This reflected in part a broader opposition to the system-Maine's Republicans had opposed the introduction of RCV from the beginning, when reformers targeted state assembly and gubernatorial elections after repeated split-vote victories by Republican Paul LePage. Ideological opposition to RCV amongst some Republicans reflected broader partisan polarization and the battle over the system's adoption at the state level. But effecting a majority choice in a multi-candidate race under RCV entails a willingness to use rankings, and the divergent partisan responses to so doing appears to have been the difference between winning and losing Maine's 2018 2nd Congressional District. As Tiffany Bond, one of the two independent candidates whose voters' rankings ultimately determined the outcome, put it at the final candidate's debate: "You'd be foolish not to rank" (Starrs \& Taylor, 2018).

\section{Conclusion}

A key message for Maine and other users of RCV in the United States from the century-long Australian experience is that rankings matter, and that party recommendations can greatly affect how voters choose to express them. Particularly in close contests, it is rational to campaign for and reciprocally offer second preferences. However, this assumes an adaptive capacity to a new electoral system which may not always be present.

What light can the comparative evidence from Australia shed on this process? First, parties can use rankings to solve coordination problems. In recent decades the left side of Australian politics has been more congested and thus requires greater coordination on preferences than the right. As a result, there is more preference-swapping activity between parties of the left and centre-left than on the right. This is compounded by the reality that conservative and single-issue voters in Australia are more likely truncate their rankings, while younger voters for progressive parties are more willing to express a range of preferences, but less likely to directly follow party instructions (Green, 2018). Third, and perhaps most importantly, we know that Australian parties and candidates strike deals to give and receive preferences more in marginal seats. When a race is tight, officeseeking candidates have a prospective incentive to make such deals before an election if they think it may benefit their prospects, regardless of whether it actually does in practice.

Another conclusion is the importance of communicating such deals to voters. In Australia, secondary rankings under RCV are driven by reciprocal signals that each party gives to their supporters. Communicating these deals to voters explicitly, via campaign material, markedly increases their potence. In the Australian state elections whose electoral system most resembles American RCV, preference flows between aligned Green and Labor candidates increased by between $10 \%$ and $20 \%$ in seats when recommended by the parties themselves. In close races, this can often be the difference between victory and defeat. Given the similarity of the two-party systems and broader social contexts, we could expect similar relationships to evolve over time in partisan RCV elections in the United States, with independents and smaller parties on the left sending preferences to Democrats and those on the right to Republicans.

However, as this article has highlighted, there are also systemic differences that are likely to limit the extent to which RCV in the United States tracks the Australian experience. Without equivalent side-benefits to those received by the major Australian parties in terms of coalition management or inter-party coordination, there is at present less incentive for the Democrat and Republican parties to champion RCV reforms for their political payoffs. American proponents have thus had to focus on broader systemic benefits such as RCV's ameliorative impacts on political polarization and campaign civility when making the case for reform. This is a much harder sell than the naked electoral benefits that accrue to Australia's major political parties from compulsory rankings at federal elections.

Such compulsion is absent both philosophically and in practice to American politics, making the kind of 
cross-partisan commitment to RCV seen in Australia less likely to develop in the United States. The Australian experience does suggest that RCV offers a plausible means to address polarisation and other pathologies, and as such represents an achievable reform to plurality voting which can have far-reaching consequences. However, the distinctive Australian proclivity for compulsion, in both preference marking and voter attendance, is unlikely to be part of the American RCV experience.

\section{Acknowledgments}

Previous versions of this article were presented at the University of Maine in 2018 and to the annual meeting of the American Political Science Association in Washington, DC in 2019. Thanks to all attendees and panellists and particularly to Amy Fried and Jack Santucci for their help and suggestions. The usual caveat applies.

\section{Conflict of Interests}

The author declares no conflict of interests.

\section{References}

Alvarez-Rivera, M. (2018, December 31). The 2018 ranked choice elections in Maine's Congressional District No. 2. Fruits and Votes. Retrieved from https://fruitsandvotes.wordpress.com/2018/12/31/ the-2018-ranked-choice-voting-election-in-mainescongressional-district-no-2

Amy, D. (2002). Real choices, new voices: How proportional representation elections could revitalize American democracy. Ithaca, NY: Columbia University Press.

Bartels, L. (2016). Failure to converge: Presidential candidates, core partisans, and the missing middle in American electoral politics. The Annals of the American Academy of Political and Social Science, 667(1), 143-65.

Brent, P. (2018, May 2). Going with the flow. Inside Story. Retrieved from https://insidestory.org.au/goingwith-the-flow

Diamond, L. (2017, November 10). How to reverse the degradation of our politics. The American Interest. Retrieved from https://www.the-american-interest. com/2017/11/10/reverse-degradation-politics

Donovan, T., Tolbert, C., \& Gracey, K. (2016). Campaign civility under preferential and plurality voting. Electoral Studies, 42, 157-163.

Drutman, L. (2019). Breaking the two-party doom loop: The case for multiparty democracy in America. New York, NY: Oxford University Press.

Fairvote. (2015). Ranked choice voting in practice: Candidate civility in ranked choice elections, 2013 \& 2014 survey brief. Fairvote. Retrieved from https:// fairvote.app.box.com/v/APSA-Civility-Brief-2015

Farrell, D. M., \& McAllister, I. (2006). The Australian elec- toral system: Origins, variations and consequences. Sydney: UNSW Press.

Fried, A., \& Glover, R. W. (2018, November 20). Maine's ranked-choice voting experiment continues. The American Prospect. Retrieved from https:// prospect.org/power/maine-s-ranked-choice-votingexperiment-continues

Graham, B. D. (1962). The choice of voting methods in federal politics, 1902-1918. Australian Journal of Politics and History, 8(2), 164-181.

Green, A. (2015). 2015 New South Wales election: Analysis of results (Background Paper No. 1/2015). Sydney: New South Wales Parliamentary Research Service.

Green, A. (2018, August 13). Preference flow data for the 2015 New South Wales election. ABC. Retrieved from https://www.abc.net.au/news/2015-08-13/ preference-flow-data-for-the-2015-nsw-election/ 9388642

Hughes, C., \& Santucci, J. (2017). History of ranked choice voting in the United States [Webinar]. Retrieved from http://www.rankedchoicevoting.org/history

Kimball, D. C., \& Anthony, J. (2017). Ranked choice voting: A different way of casting and counting votes. In T. Donovan (Ed.), Changing how America votes (pp. 100-112). Lanham, MD: Rowman \& Littlefield.

Maloy, J. S. (2019). Smarter ballots: Electoral realism and reform. London: Palgrave Macmillan.

Phillips, H. (2008). Electoral law in the State of Western Australia: An overview. Perth: Western Australian Electoral Commission. Retrieved from https:// www.elections.wa.gov.au/sites/default/files/ content/documents/Electoral_Law_WA_3rd.pdf

Reilly, B. (2001). Democracy in divided societies: Electoral engineering for conflict management. Cambridge: Cambridge University Press.

Reilly, B. (2016). Democratic design and democratic reform: The case of Australia. Taiwan Journal of Democracy, 12(2), 1-16.

Reilly, B. (2018). Centripetalism and electoral moderation in established democracies. Nationalism and Ethnic Politics, 24(2), 201-221.

Reilly, B., \& Maley, M. (2000). The single transferable vote and the alternative vote compared. In S. Bowler \& B. Grofman (Eds.), Elections in Australia, Ireland and Malta under the single transferable vote: Reflections on an embedded institution (pp. 37-58). Ann Arbor, MI: University of Michigan Press.

Reilly, B., \& Stewart, J. (2021). Compulsory preferential voting, social media and 'come-from-behind' electoral victories in Australia. Australian Journal of Political Science, 56(1), 99-112. https://doi.org/10.1080/ 10361146.2021.1879010

Richie, R. (2004). Instant runoff voting: What Mexico and others can learn. Election Law Journal, 3(3), 501-512.

Santucci, J. (2017). Party splits, not progressives: The origins of proportional representation in American local government. American Politics Research, 45(3), 494-526. 
Santucci, J. (2018). Maine ranked-choice voting as a case of electoral-system change. Representation, 54(3), 297-311.

Sharman, C., Sayers, A. M., \& Miragliotta, N. (2002). Trading party preferences: The Australian experience of preferential voting. Electoral Studies, 21(4),
543-560.

Starrs, J., \& Taylor, D. (2018, November 1). Can rankedchoice voting end ugly election battles? This November, Maine hopes to find out. The Washington Post. Retrieved from www.washingtonpost.com

\section{About the Author}

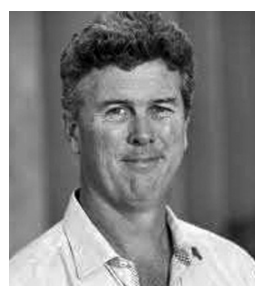

Benjamin Reilly is a Professor of Political Science and International Relations at the University of Western Australia. He was formerly Dean of the Sir Walter Murdoch School, Director of the Centre for Democratic Institutions at the Australian National University (ANU), and has held visiting appointments at Harvard, Oxford, and Johns Hopkins (SAIS) universities. His work focusses on democracy, democratization and political institutions. He holds a PhD in Political Science from the ANU. 